\title{
Thermosensitive Ni-Based Magnetic Particles for Self-Controlled Hyperthermia Applications
}

Sudip Pandey ${ }^{1}$, Abdiel Quetz ${ }^{1}$, Anil Aryal ${ }^{1}$, Igor Dubenko ${ }^{1}$, Dipanjan Mazumdar ${ }^{1}$, Shane Stadler ${ }^{2}$, and Naushad $\mathrm{Ali}^{1}$

${ }^{1}$ Department of Physics, Southern Illinois University, Carbondale, IL 62901 USA

${ }^{2}$ Department of Physics \& Astronomy, Louisiana State University, LA 70803 USA

A number of ferromagnetic alloys in the bulk-form "thermoseeds" have been investigated for localized self-controlled hyperthermia treatment of cancer by substituting $\mathrm{V}, \mathrm{Mo}, \mathrm{Cu}$, and $\mathrm{Ga}$ for Ni. The samples were prepared by arc-melting technique and annealed at $1223 \mathrm{~K}\left(950{ }^{\circ} \mathrm{C}\right)$ for 12 hours in sealed quartz tubes. The structural, magnetic, and magnetocaloric properties of the samples were studied, using room temperature X-ray diffraction and a Superconducting Quantum Interference Device (SQUID) magnetometer. The magnetocaloric parameters (magnetic entropy changes, refrigeration capacity (RC), and hysteretic effects) have been calculated. It has been shown that recrystallization, i.e., annealing time and temperature, is crucial for controlling the heating characteristics of the seeds. A linear decrease in Curie temperature $\left(\mathrm{T}_{\mathrm{C}}\right)$ from $380 \mathrm{~K}\left(107{ }^{\circ} \mathrm{C}\right)$ to $200 \mathrm{~K}\left(-73{ }^{\circ} \mathrm{C}\right)$ was observed with increasing substitution of $\mathrm{Ni}$ by $\mathrm{V}, \mathrm{Mo}, \mathrm{Cu}$, and $\mathrm{Ga}$, while the magnetization value remained nearly constant for all substitutions. The optimal composition of these Ni-based alloys has been determined in order to allow self-controlling hyperthermia, implying a Curie temperature near the therapeutic level, 315-318 $\mathrm{K}\left(41-45{ }^{\circ} \mathrm{C}\right)$. The results showed that an extraordinary self-regulating heating effect has been achieved in Ni-based magnetic materials, which may create new vistas for hyperthermia cancer treatment. 


\section{INTRODUCTION}

Hyperthermia is a rapidly developing treatment method for cancer in which the target tissue is heated above the normal body temperature [1-5]. Hyperthermia has been used for many years to treat a wide variety of tumors in patients and also used in conjunction with other forms of cancer therapy, such as radiation therapy and chemotherapy $[6,7]$. This method is used to increase the temperature of a tumor to $315-318 \mathrm{~K}\left(41-45^{\circ} \mathrm{C}\right)$ because temperatures higher than $314 \mathrm{~K}$ reduce the viability of a tumor cell [8-10]. The healthy cells can withstand such conditions, while the cancer cells cannot. When tumor cells are heated, the blood vessels are unable to dilate, resulting in the poor dissipation of heat as the tumor is a tightly packed group of cells having poor blood circulation. The poor dissipation of heat in tumor accumulates harmful metabolic byproducts and low $\mathrm{pH}$, resulting the self-destruction of the abnormal growth [11].

Conventional hyperthermia treatment is fulfilled by heating the patient's body in a water bath (general hyperthermia) and by applying radio and microwave radiation (local hyperthermia). There are many side effects of these convention hyperthermia methods due to an uneven spread of heat inside the tumor and tissue. This inspired the development of a new method in which "local" heating was achieved due to remagnetization losses in magnetic materials referred to as magnetic hyperthermia $[12,13]$. This magnetic hyperthermia allows a more uniform dissemination of heat and therefore the side effects are not as severe as in conventional hyperthermia methods. In magnetic hyperthermia the temperature of body is heated up to a certain temperature using magnetic thermoseeds or magnetic nanoparticles subjected to alternating magnetic fields. The most common method of heating in magnetic particles is to take advantage of the hysteresis in ferromagnetic particles to release heat. Other methods of heating 
take advantage of relaxation losses in supermagnetic particles $[14,15]$. The specific absorption rate $(\mathrm{SAR})$ is a parameter quantifies the transformation of the energy of the alternating electromagnetic field into heat, which is calculated as:

$$
\mathrm{SAR}=\text { f. } X
$$

where $\mathrm{f}$ is the frequency of the electromagnetic field and $\mathrm{X}$ is the hysteresis area, i.e., specific energy observed in one cycle of remagnetization:

$$
\mathrm{X}=\int \mathrm{H} \mathrm{dB}
$$

where B is the magnetic induction. Therefore, highly hysteretic magnetic particles are desirable.

Another mechanism of heating which is different from the local magnetic hyperthermia effect is the magnetocaloric effect (MCE) [16-19]. At present main research for the for the magnetocaloric materials is directed for the magnetic refrigeration. However we try to use another perspective applications of these materials in the field of medicine. The MCE occurs as the result of the alignment of magnetic moments with an external applied magnetic field. The alignment reduces the magnetic randomness, or the magnetic component of the total entropy. This reduction of magnetic entropy must be compensated by the increase of another form of entropy and, in the case of magnetocaloric (MC) materials, is channeled into phonons, or heat. Because the mechanism of heating in this case is different from that of the conventional magnetic hyperthermia, it is named as "magnetocaloric hyperthermia [20]. There are three quantities that are usually reported for MCE: the magnetic entropy change $\left(\Delta \mathrm{S}_{\mathrm{M}}\right)$, the refrigeration capacity $(\mathrm{RC})$, and the adiabatic temperature change $(\Delta \mathrm{T})$. For a thermodynamic Carnot cycle the energy observed in one cycle in a magnetocaloric material is calculated as [20, 21]:

$$
\Delta \mathrm{Q}=\Delta \mathrm{T} \cdot \Delta \mathrm{S}_{\mathrm{M}}
$$


Thus, the magnetocaloric contribution to heating in this type of hyperthermia is significant for a materials with large MCE parameters.

Magnetic losses in magnetically ordered ferro- and ferri-magnetic materials have a number of advantages as they diminish at the Curie temperature $\left(\mathrm{T}_{\mathrm{C}}\right)$. As a result, magnetic hyperthermia treatments could be free from external temperature control when $T_{C}$ is tuned to the therapeutic temperature range. In order to prevent the overheating of normal cells, the development of magnetic materials which are not affected by alternating magnetic field above $318 \mathrm{~K}\left(45^{\circ} \mathrm{C}\right)$ has become essential. Nowadays, much of the research is focused on candidate materials composed of noble metals, rare-earth metals, their respective alloys, and intermetallic compounds. Ni-Cr [22], $\mathrm{Fe}_{3} \mathrm{O}_{4}$ [23], $\mathrm{Cu}-\mathrm{Ni}$ [24], $\mathrm{La}-\mathrm{Ag}$ and $\mathrm{La}-\mathrm{Na}$ [25], and $\mathrm{Gd}_{5}\left(\mathrm{Si}_{1-\mathrm{x}} \mathrm{Ge}_{\mathrm{x}}\right)_{4}$ and $\left(\mathrm{Gd}_{1-\mathrm{x}} \mathrm{Er}_{\mathrm{x}}\right)_{5} \mathrm{Si}_{4}[26]$ have been investigated as thermoseeds and nanoparticles for use in the localized self-controlled hyperthermia treatment for cancer. Recently, Bhoj Raj Gautam, et.al, explain the possibility of using the self-regulating Ni based seed encapsulated in titanium capsule for the treatments of solid Tumors [27]. We believed that these materials are applicable for medical propose as large numbers of research is going on for the Ni-based alloys for the hyperthermia treatment of cancer.

The objective of this study was to synthesis the Ni-based alloys with different compositions in which large, self-regulated heating powers occur at the precisely correct temperature to be used as a safe and effective form of hyperthermia treatment of cancer cells. These magnetic materials not only heat rapidly but the heating effect also stops abruptly after the temperature exceeds that needed to destroy tumor tissue, keeping it too low to affect normal healthy tissue. This may lead to a unique self-regulated heating effect with a large loss power which is unmatched by other conventional ferromagnetic materials. 
In the present work, detailed studies of the crystal structural and magnetic properties have been performed for $\mathrm{Ni}_{1-\mathrm{X}} \mathrm{Z}_{\mathrm{x}}(\mathrm{Z}=\mathrm{V}, \mathrm{Mo}, \mathrm{Cu}$, and $\mathrm{Ga})$ binary alloys as a thermoseeds for hyperthermia applications. We present experimental result that reveal a linear change in magnetic ordering temperatures over a wide range with the change in doping concentrations. The main aim of this paper was to explore magnetic materials that have properties suitable for use in self-controlled magnetic hyperthermia, i.e., Curie temperature equal to $318 \mathrm{~K}\left(45^{\circ} \mathrm{C}\right)$.

\section{EXPERIMENTAL TECHNIQUES}

Three grams samples of $\mathrm{Ni}_{1-\mathrm{x}} \mathrm{Z}_{\mathrm{x}}(\mathrm{Z}=\mathrm{V}, \mathrm{Mo}, \mathrm{Cu}$, and $\mathrm{Ga})$ binary alloys were fabricated by conventional arc-melting in an argon atmosphere using high purity (4N) elements. The ingots were re-melted four times to ensure homogeneity. The alloys with $<0.2 \%$ weight loss were considered for the study. The samples were annealed at $1223 \mathrm{~K}\left(950{ }^{\circ} \mathrm{C}\right)$ for 12 hours in high vacuum $\left(\approx 10^{-4}\right.$ torr $)$ and cooled at a rate of $4{ }^{\circ} \mathrm{C}$ per minute to room temperature. The phase purity and crystal structures were determined by powder X-ray diffraction (XRD) using $\mathrm{Cu} \mathrm{Ka}$ radiation. The magnetic and magnetocaloric properties were measured using a Quantum Design superconducting quantum interference device magnetometer (Quantum Design, Inc.) in a temperature range of $10 \mathrm{~K}$ to $400 \mathrm{~K}$ and in magnetic fields up to $5 \mathrm{~T}$. The magnetic entropy changes $\left(\Delta \mathrm{S}_{\mathrm{M}}\right)$ values were calculated from isothermal magnetization curves using the Maxwell relation (28). The refrigeration capacity (RC) has been calculated by integrating $\Delta \mathrm{S}_{\mathrm{M}}(\mathrm{T}, \mathrm{H})$ curve over the full width at half maximum using relation (2) [29].

$$
\begin{aligned}
& \Delta S_{M}(T, H)=\int_{0}^{H}\left(\frac{\partial M(T, H)}{\partial T}\right)_{H} d H \\
& \mathrm{RC}=\int_{T_{1}}^{T_{2}} \Delta \mathrm{S}_{M}(T) d T
\end{aligned}
$$




\section{RESULTS AND DISCUSSION}

The room temperature XRD patterns of $\mathrm{Ni}_{1-\mathrm{x}} \mathrm{Z}_{\mathrm{x}}(\mathrm{Z}=\mathrm{V}, \mathrm{Mo}, \mathrm{Cu}$, and $\mathrm{Ga})$ are shown in Fig. 1. All compounds possess a cubic phase which is similar to the XRD patterns of pure Ni without extra or split peaks. The small peak at low angle corresponds to beta line of $\mathrm{Cu}$ Ka radiation. Thus, single phase composition was achieved over the full range of $\mathrm{Z}$ concentrations.

The magnetization versus temperature data measured in a field $\mathrm{H}=100$ Oe for annealed $\mathrm{Ni}_{1-\mathrm{x}} \mathrm{Z}_{\mathrm{x}}(\mathrm{Z}=\mathrm{V}, \mathrm{Mo}, \mathrm{Cu}$, and $\mathrm{Ga})$ alloys are shown in Fig. 2. Similar types of $\mathrm{M}(\mathrm{T})$ curves have been detected for all concentrations. The data show that there is a clear indication of the magnetic transformation (Curie transition) at different temperatures depending on $\mathrm{x}$. The annealed sample shows a sharp Curie transition, whereas the un-annealed sample does not show a clear transition (see Figure 1 in supplementary information). This is because annealing eliminates residual stresses and lattice defects, allowing for the recrystallization and refining of the magnetic properties [30]. This indicates that the heat treatment has a strong influence on the magnetic properties of these Ni-based alloys. Also from Fig. 2, one can see that a systematic decrease in the Curie temperature with increasing V, Mo, $\mathrm{Cu}$, and $\mathrm{Ga}$ concentrations while the magnetization values remain relatively constant. The values of magnetization obtained were (68) emu/g, which were $400 \%$ larger than those reported for the Ni-based alloys in Ref. [22, 30]. Since the heat generated is proportional to the magnetization, a material with higher magnetization in the ferromagnetic region will provide a greater heating power. 
Ferromagnetic materials exhibit a spontaneous magnetization below the Curie temperature $\left(\mathrm{T}_{\mathrm{C}}\right)$. Since the precise determination of the Curie temperature is critical for hyperthermia applications, the $\mathrm{T}_{\mathrm{C}}$ value of our samples were estimated by different methods. The $\mathrm{T}_{\mathrm{C}}$ values of alloys were determined from the maximum of differential magnetization (dM/dT) of the $\mathrm{M}(\mathrm{T})$ curves with respect to temperature. Curie temperature versus the $\mathrm{V}, \mathrm{Mo}, \mathrm{Cu}$, and $\mathrm{Ga}$ concentrations were shown in Fig. 3. One can see that the Curie temperature decreases with increasing $\mathrm{V}, \mathrm{Mo}, \mathrm{Cu}$, and $\mathrm{Ga}$ concentrations. It shows that the desired Curie temperature $(315 \mathrm{~K}$ $-318 \mathrm{~K})$ can be tuned precisely in $\mathrm{Ni}_{1-\mathrm{x}} \mathrm{Z}_{\mathrm{x}}(\mathrm{Z}=\mathrm{V}, \mathrm{Mo}, \mathrm{Cu}$, and $\mathrm{Ga})$ alloys by adjusting $\mathrm{Z}$ concentration without any significant loss of magnetization. We also employed Arrott plot analysis $\left(\mathrm{H} / \mathrm{M}\right.$ vs. $\left.\mathrm{M}^{2}\right)$ and power laws analysis $\left(\mathrm{M}^{3}\right.$ vs. $\left.\mathrm{T}\right)$ to determine the Curie temperatures (see supplementary information). The value of $\mathrm{T}_{\mathrm{C}}$ calculated from the Arrott plots and from the power law are in good agreement with those obtained from the minimum of $d M / d T$ in the $M(T)$ curves. We observe that the $\mathrm{T}_{\mathrm{C}}$ values obtained by different methods results in remarkably identical values.

The field dependence of the magnetization $\mathrm{M}(\mathrm{H})$ curves of $\mathrm{Ni}_{1-\mathrm{x}} \mathrm{Z}_{\mathrm{x}}(\mathrm{Z}=\mathrm{V}, \mathrm{Mo}, \mathrm{Cu}$, and $\mathrm{Ga}$ ) at $\mathrm{T}=10 \mathrm{~K}$ for different compositions are shown in Fig. 4. All of the compounds exhibit ferromagnetic or ferrimagnetic type behavior with a magnetization at $\mathrm{H}=5 \mathrm{~T}$ of about $30-35$ emu/g. The saturation field is observed to decrease for increasing $\mathrm{V}, \mathrm{Mo}, \mathrm{Cu}$, and $\mathrm{Ga}$ concentrations. (see Fig. 4). The saturation magnetization at $10 \mathrm{~K}(\mathrm{H}=5 \mathrm{~T})$ decreases almost linearly with increasing $\mathrm{V}, \mathrm{Mo}, \mathrm{Cu}$, and $\mathrm{Ga}$ concentrations. The curves for the studied systems (see in Fig. 5) demonstrate the maximum magnetization observed for the Ni-based alloys under investigation with respect to the concentration of conduction electrons per atom (e/A). The e/A parameter has been calculated using a common approach "Vasil'ev", as number of outer shell 
electrons introduced into conduction by each alloy's chemical elements over the average number of atoms in alloy. For example, the electronic structure of $\mathrm{Ni}_{075} \mathrm{Si}_{0.25}$ is formed (see periodical table) by $0.75 \cdot\left[3 \mathrm{~d}^{7} 4 \mathrm{~s}^{2}\right]_{\mathrm{Ni}}+0.25 \cdot\left[3 \mathrm{~s}^{2} \mathrm{p}^{2}\right]_{\mathrm{Si}}=6.75 \mathrm{e}_{\mathrm{Ni}}+1 \mathrm{e}_{\mathrm{Si}}=7.75 \mathrm{e}$. Thus, for these alloys $\mathrm{e} / \mathrm{A}=7.75 \mathrm{e} / \mathrm{A}$. The obtained magnetization result shows a maximum magnetization similar to the other Slater-Pauling curves Thus, the observed decrease in the magnetization and in transition temperatures (see in Fig.3 and Fig. 4) can be related to the decrease in the Ni-Ni exchange interaction.

The magnetic entropy changes $\left(\Delta \mathrm{S}_{\mathrm{M}}\right)$ in the vicinity of $\mathrm{T}_{\mathrm{C}}$ for different magnetic fields $(\Delta \mathrm{H})$ are shown in Fig. 6. Also from Fig. 6 we can see that the $\mathrm{Ni}_{1-\mathrm{x}} \mathrm{Z}_{\mathrm{x}}(\mathrm{Z}=\mathrm{V}, \mathrm{Mo}, \mathrm{Cu}$, and $\mathrm{Ga})$ alloys exhibit $\Delta \mathrm{S}_{\mathrm{M}}$ around (1-1.7) $\mathrm{J} / \mathrm{kg} \mathrm{K}$. These values of $\Delta \mathrm{S}_{\mathrm{M}}$ near $\mathrm{T}_{\mathrm{C}}$ are due to jump-like changes in the magnetization from a FM ordered phase to a PM disordered phase, corresponding to SOTs which are evident in the $\mathrm{M}(\mathrm{T})$ curves (Fig. 2). It is also interesting to note that $\Delta \mathrm{S}_{\mathrm{M}}(\mathrm{T})$ spanned a wide temperature range. Such flat distributions of MCE properties are important for practical applications. Also it should be noted that the advantage of using materials with a large MCE at a SOT is the complete reversibility of the magnetization process. The magnitude of the magnetization changes remain relatively constant for all concentrations, which results in a similar $\Delta \mathrm{S}_{\mathrm{M}}$ values for all of the alloys. Magnetocaloric hyperthermia has several potential advantages over local hyperthermia such as: low frequency alternating electromagnetic fields which reduces the harm from its effects on the body, the possibility of simultaneously performing the MCE hyperthermia procedure with drug delivery, and the possibility to deliver and hold the magnetic particles in the tissue with the help of magnetic fields. Also, targeted drug delivery by using MCE materials only affects the source of inflammation, leaving the rest of the body unaffected. For a single demagnetization or magnetization of the magnetic particles, the 
heat absorbed or released for $\mathrm{V}_{6.15}$ and $\mathrm{Cu}_{27.8}$ are $2.8 \mathrm{~mJ} / \mathrm{g}$, and $1.6 \mathrm{~mJ} / \mathrm{g}$, respectively, in a field of $2 \mathrm{~T}$ at Curie temperature close to human body temperature. These values are smaller than the value observed in $\mathrm{Fe}_{0.49} \mathrm{Rh}_{0.51}$ [31]. Another important parameter to evaluate the MCE potential of a given material is the refrigeration capacity (RC). Because the refrigeration capacity is a measure of a system's ability to remove heat, this parameter can be important when it is necessary to cool down the alloy after heating it to required temperature. The maximum RC values were found to be $153 \mathrm{~J} / \mathrm{kg}, 138 \mathrm{~J} / \mathrm{kg}$, and $113 \mathrm{~J} / \mathrm{kg}$ for a field change of $\Delta \mathrm{H}=5 \mathrm{~T}$ for $\mathrm{V}_{6.15}$, $\mathrm{Mo}_{4.9}$, and $\mathrm{Ga}_{10.5}$, respectively. The MCE and the change in the alloy temperature $(\Delta \mathrm{T})$ depend on $2 / 3$ power function of applied magnetic field in the case of second order transition [32]. Thus, it seems that it would be possible to choose the proper magnetic field for human treatment by using MCE materials. Hence, the observed MCE parameters near the SOT and tunable transition temperatures make this system an attractive potential magnetic material for the treatment of cancer by the method of magnetocaloric hyperthermia.

\section{CONCLUSION}

The crystal structure, Curie temperatures, magnetic contributions to entropy changes associated with $\mathrm{T}_{\mathrm{C}}$, and refrigeration capacities, have been studied in Ni-based alloys. A linear decrease in $\mathrm{T}_{\mathrm{C}}$ from $380 \mathrm{~K}\left(107^{\circ} \mathrm{C}\right)$ to $200 \mathrm{~K}\left(-73^{\circ} \mathrm{C}\right)$ was observed with increasing substitution of Ni by $\mathrm{V}$, $\mathrm{Mo}, \mathrm{Cu}$, and $\mathrm{Ga}$, while the magnetization values remained relatively constant. The desired Curie temperature for hyperthermia treatment of cancer, $318 \mathrm{~K}\left(45^{\circ} \mathrm{C}\right)$ was obtained for $\mathrm{Ni}_{93.85} \mathrm{~V}_{6.15}$, $\mathrm{Ni}_{72.2} \mathrm{Cu}_{27.8}, \mathrm{Ni}_{94.8} \mathrm{Mo}_{5.2}$, and $\mathrm{Ni}_{89.2} \mathrm{Ga}_{10.8}$ binary alloys. A new hyperthermia method based on the magnetocaloric effect has been discussed. About 400\% larger values of magnetization near (6-8) emu/g were obtained than those reported for the Ni-based alloys. Hence we were able to synthesize a number of Ni-based alloys that may be used as thermoseeds by tuning the Curie 
points to achieve thermal self-regulation, thereby eliminating the costly and invasive thermometry now associated with hyperthermia treatments.

Acknowledgements: This work was supported by the Office of Basic Energy Sciences, Material Science Division of the U.S. Department of Energy DOE Grant No. DE-FG02-06ER46291 (SIU) and DE-FG02-13ER46946 (LSU).

\section{References:}

[1] R. Jayasundar, L. D. Hall, and N. M. Bleehen, Magn. Reson. Imaging 19, 111 (2001).

[2] Q. A. Pankhurust, J. Connolly, S. K. Jones, J. Dobson, J. Phys. D, 36, R167-R181, 2003.

[3] M. Babincova, V. Altanerova, E. Altaner, Z. Baeova, and P. Babinec, Eur. Cells Mater 3, Suppl. 2, 140 (2002).

[4] D. G. Gonzlez, J. Overgaard, and M. C. C. M. Hulshof, Lancet 345, 540 (1995).

[5] J. W. Hand, C. C. Vernon, and S. B. Field, Int. J. Radiat. Oncol. Phys. 35, 731 (1996).

[6] J. J. W. Lagendijk, Phys. Med. Biol. 45, R61 (2000).

[7] P. Wust, B. Hildebrandt, G. Sreenivasa, B. Rau, J. Gellermann, H. Riess, R. Felix, and P. M. Schlag, Lancet Oncol. 3, 487 (2002).

[8] Y. Harima, K. Nagata, K. Harima, V. V. Ostapenko, Y. Tanaka, and S. Sawada. Int. J. Hyperthermia 17, 97 (2001).

[9] M. Kakehi, K. Ueda, and T. Mukojima. Int. J. Hyperthermia 6, 719 (1990).

[10] K. Kitamura, H. Kuwano, and M. Watanabe. J. Surg. Oncol. 60, 55 (1995). 
[11] H. S. Reinhold, and B. Endrich. Int. J. Hyperthermia 2,111 (1986).

[12] S. Deger, K. Taymoorian, D. Boehmer, T. Schink, J. Roigas, A. H. Wille, V. Budach, K. D. Wernecke, and S. A. Loening, Europ. Urol. 45, 574 (2004).

[13] S. Mornet, S. Vasseur, F. Grasset, and E. Duguet, J. Mat. Chem. 14, 2161 (2004).

[14] Q. A Pankhurst, J. Connolly, S. K. Jones and J. Dobson, J. Phys. D 36, R167 (2003).

[15] R. Hergt, W. Andra, "Magnetic Hyperthermia and Thermoablation" in "Magnetism in Medicine”, Eds. W. Andra and H. Nowak, Second Edition (Wiley-VCH Verlag 2006).

[16] A. M Tishin, and Y. I. Spichkin, The magnetocaloric effects and its applications, Institute of Physics Publishing, Series in Condensed Matter Physics, ISBN 075030922 9, Bristol, 2003.

[17] A. M Tishin, and Y. I. Spichkin, International Journal of Refrigeration 37, 223-229 (2014).

[18] M. R. Barati, C. Selomulya, K. G. Sandeman, and K. Suzuki, Appl. Phys. Lett. 105, $162412(2014)$.

[19] A. M, Tishin, 2006, Method for carrying out a magnetic therapy of malignant neoplasm. WO 2006/135270 Al.

[20] E. Zatsepina, A. Tishin, P. W. Egolf, D. Vuamoz, Third Int. conf. on the magnetic refrigeration at room temperature, USA, 12-15 May 2009.

[21] M. Johannesen, U. Gneveckow, L. Eckelt, A. Feussner, N. Waldoenfer, R. Scholoz, S. Deger, P. Wust, S.A. Loening, A. Jordan, Int. J. Hyperthermia 21 (7), 637-647. 
[22] Akin Y, Obaidat IM, Issa B, Haik Y (2009) Ni1-xCrx alloy for self-controlled magnetic hyperthermia. Crystal Research and Technology 44: 386-390.

[23] R. Hergt, Andra W, d'Ambly CG, Hilger I, Kaiser WA, et al. (1998) Physical limits of hyperthermia using magnetite fine particles. IEEE Trans Magn 34: 3745-3754.

[24] A. A. Kuznetsova, V. G. Leontievb, V.A Brukvinb, G. N. Vorozhtsovc, B. Y. Koganc, J Magn. Magn. Mater 311, 197-203 (2007).

[25] O. A. Shlyakhtin, V. G. Leontiev, Y. J. Oh, A. A. Kuznetsov, 16, N35-N39 (2007).

[26] S. N. Ahmad, and S. A. Shaheen, J Appl. Phys. 106, 064701(2009).

[27] B. Gautam, D. Shvydka, M. Subramanian, and E. I. Parsai, Med. Phys. 38, 3733 (2011).

[28] S. Y. Yu, Z. H. Liu, G. D. Liu, J. L. Chen, Z. X. Cao, G. H. Wu, B. Zhang, X. X. Zhang, Appl. Phys. Lett. 89, 162503 (2006).

[29] K. A. Gschneidner Jr., V. K. Pecharsky, and A. O. Tsokol, Rep. Prog. Phys. 681479 (2005).

[30] B. R. Gautam, Study of Dosimetric and Thermal Properties of a Newly Developed Thermo-brachytherapy Seed for Treatment of Solid Tumors (2013).

[31] M. P Annaorazov, K. A. Asatryan, G. Myalikgulyev, S. A. Nikrtin, A. M. Tishin, A. L. Tyurin, Cryogenics 32, 867-872 (1992).

[32] H. Oesterreicher, F.T. Parkar, J. of Appl. Phys. 55, 4334 (1984). 


\section{Figure Captions:}

Fig. 1. Room temperature $\mathrm{XRD}$ patterns of selected $\mathrm{Ni}_{1-\mathrm{x}} \mathrm{Z}_{\mathrm{x}}(\mathrm{Z}=\mathrm{V}, \mathrm{Mo}, \mathrm{Cu}$, and $\mathrm{Ga})$ binary alloys.

Fig. 2. Magnetization (M) vs. temperature (T) data of various $\mathrm{Ni}_{1-\mathrm{x}} \mathrm{Z}_{\mathrm{x}}(\mathrm{Z}=\mathrm{V}, \mathrm{Mo}, \mathrm{Cu}$, and $\mathrm{Ga})$ alloys in an applied magnetic field of 100 Oe.

Fig. 3. Variation of the Curie temperatures $\left(\mathrm{T}_{\mathrm{C}}\right)$ with $\mathrm{V}, \mathrm{Mo}, \mathrm{Cu}$, and $\mathrm{Ga}$ concentrations.

Fig. 4. Magnetization $(M)$ as a function of magnetic field at $\mathrm{T}=10 \mathrm{~K}$ for $\mathrm{Ni}_{1-\mathrm{x}} \mathrm{Z}_{\mathrm{x}}(\mathrm{Z}=\mathrm{V}, \mathrm{Mo}, \mathrm{Cu}$, and $\mathrm{Ga}$ ) alloys.

Fig. 5 Magnetization as a function of conduction electrons concentration (e/A) for $\mathrm{Ni}_{1-\mathrm{x}} \mathrm{Z}_{\mathrm{x}}(\mathrm{Z}=\mathrm{V}$, $\mathrm{Mo}, \mathrm{Cu}$, and $\mathrm{Ga}$ ) alloys (Slater-Pauling curves).

Fig. 6. Magnetic entropy changes $\left(\Delta \mathrm{S}_{\mathrm{M}}\right)$ of selected $\mathrm{Ni}_{1-\mathrm{x}} \mathrm{Z}_{\mathrm{x}}(\mathrm{Z}=\mathrm{V}, \mathrm{Mo}, \mathrm{Cu}$, and $\mathrm{Ga})$ alloys for a magnetic field change of $\Delta \mathrm{H}=5 \mathrm{~T}$. 


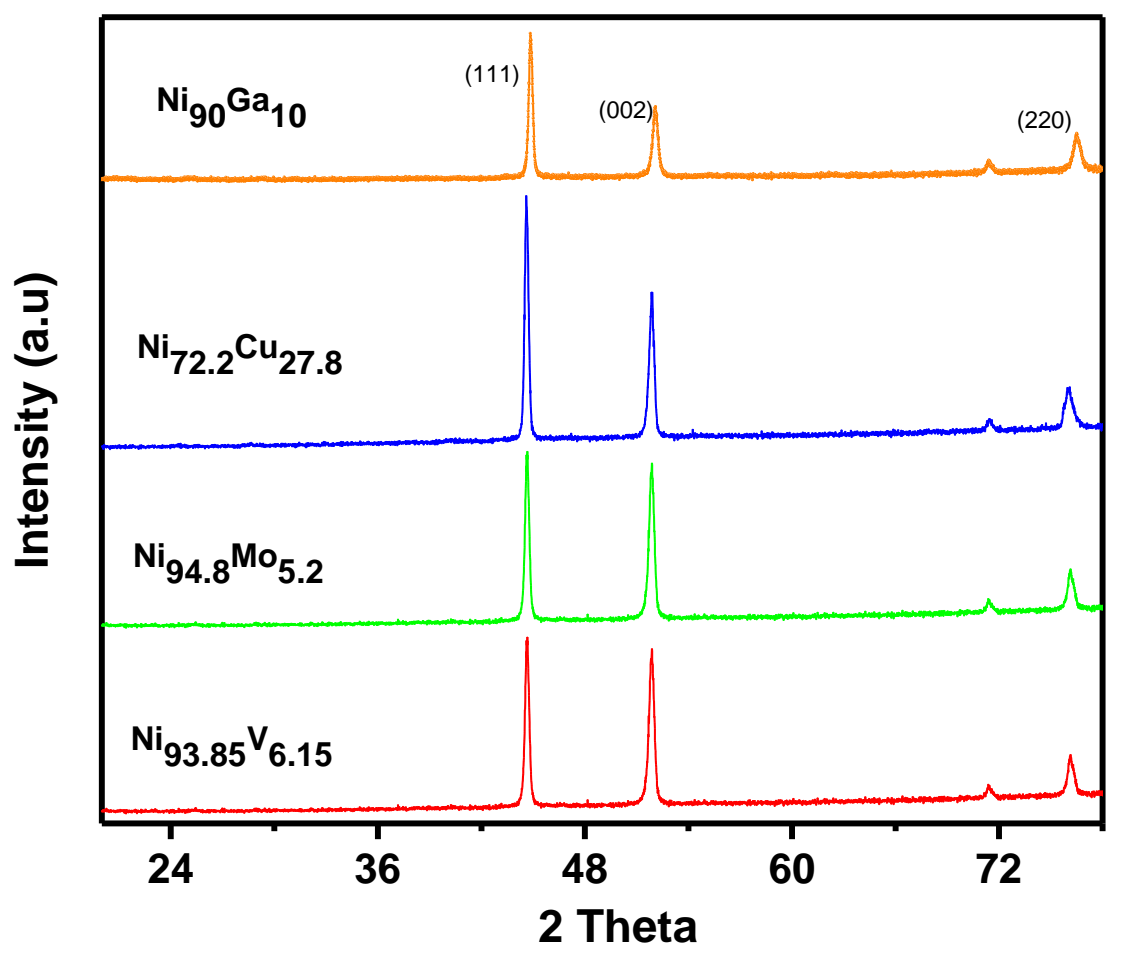

Fig. 1. Room temperature $X R D$ patterns of selected $\mathrm{Ni}_{1-\mathrm{X}} \mathrm{Z}_{\mathrm{x}}(\mathrm{Z}=\mathrm{V}, \mathrm{Mo}, \mathrm{Cu}$, and $\mathrm{Ga})$ binary alloys. 

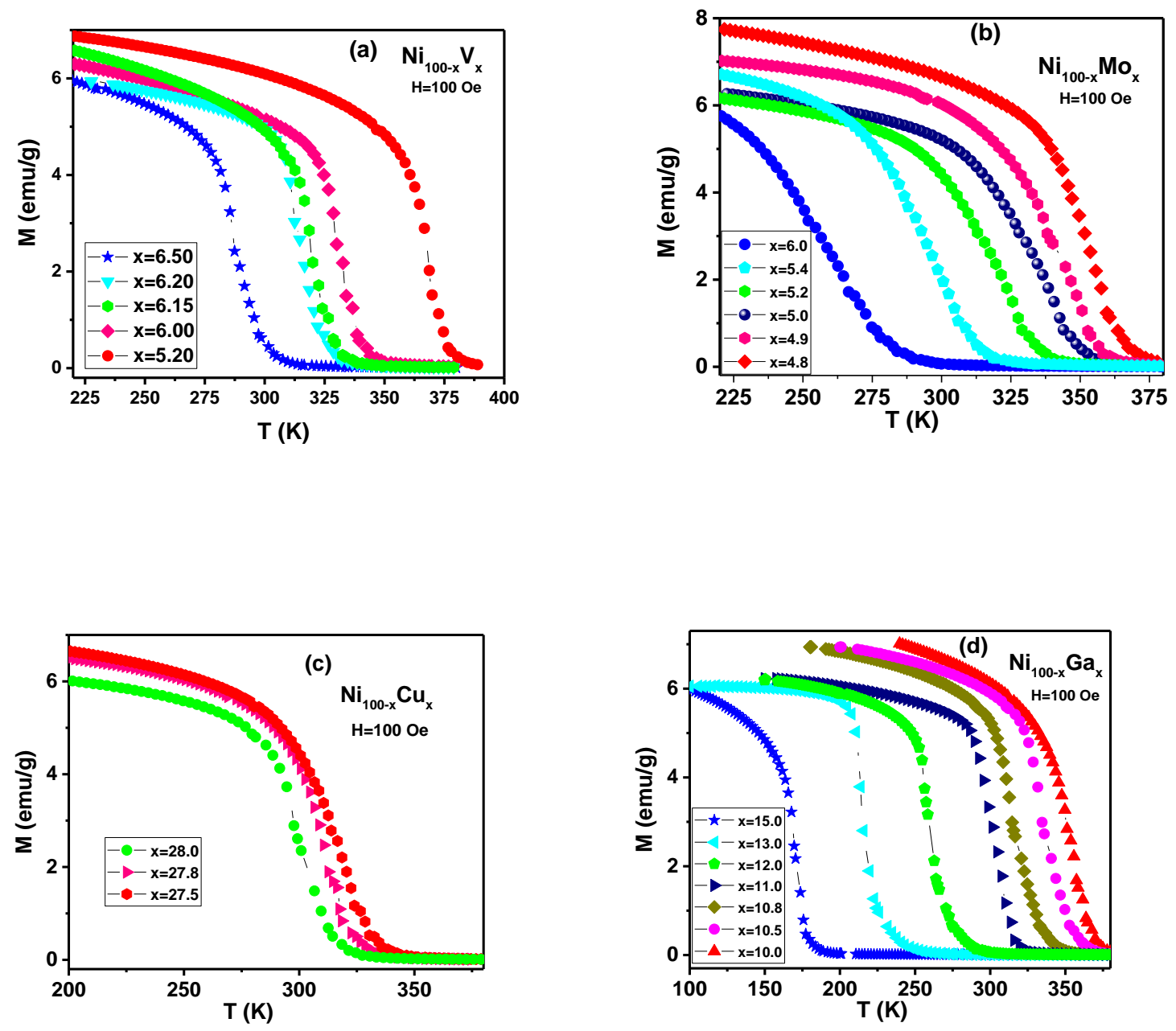

Fig. 2. Magnetization (M) vs. temperature (T) data of various $\mathrm{Ni}_{1-\mathrm{x}} \mathrm{Z}_{\mathrm{x}}(\mathrm{Z}=\mathrm{V}, \mathrm{Mo}, \mathrm{Cu}$, and $\mathrm{Ga})$ alloys in an applied magnetic field of 100 Oe. 


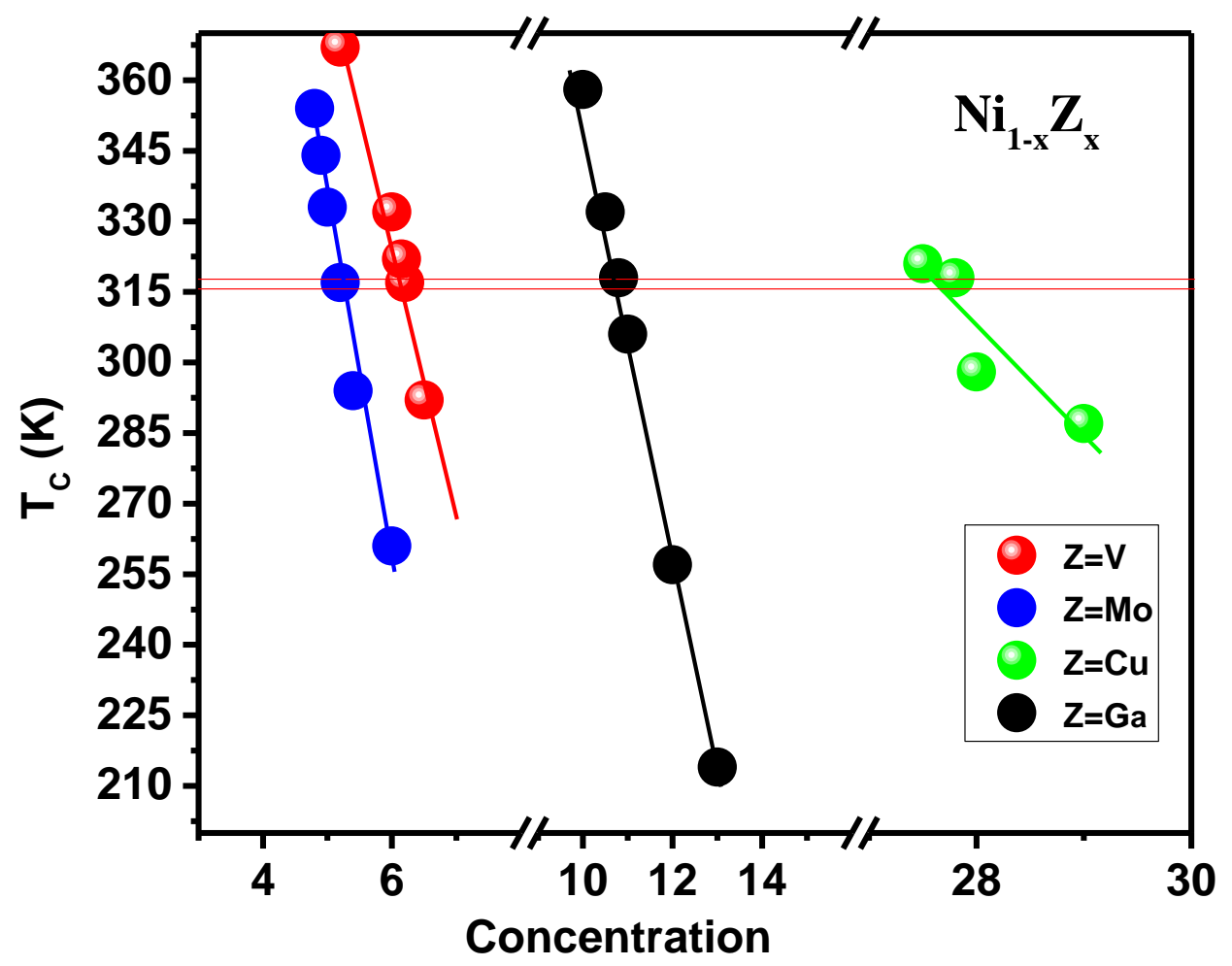

Fig. 3. Variation of the Curie temperatures $\left(\mathrm{T}_{\mathrm{C}}\right)$ with $\mathrm{V}, \mathrm{Mo}, \mathrm{Cu}$, and $\mathrm{Ga}$ concentrations. 

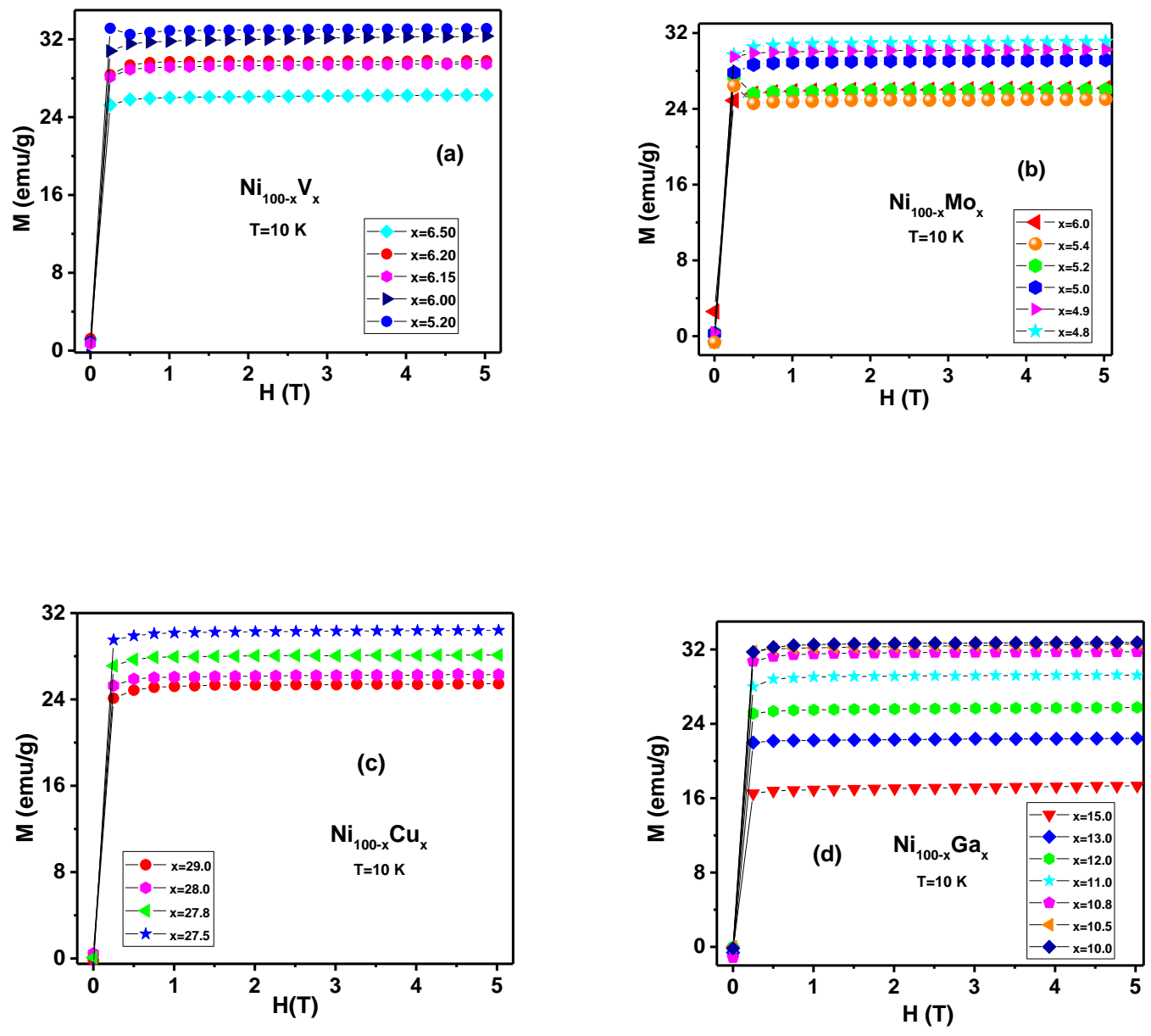

Fig. 4. Magnetization (M) as a function of magnetic field at $\mathrm{T}=10 \mathrm{~K}$ for $\mathrm{Ni}_{1-\mathrm{x}} \mathrm{Z}_{\mathrm{x}}(\mathrm{Z}=\mathrm{V}, \mathrm{Mo}, \mathrm{Cu}$, and $\mathrm{Ga}$ ) alloys. 


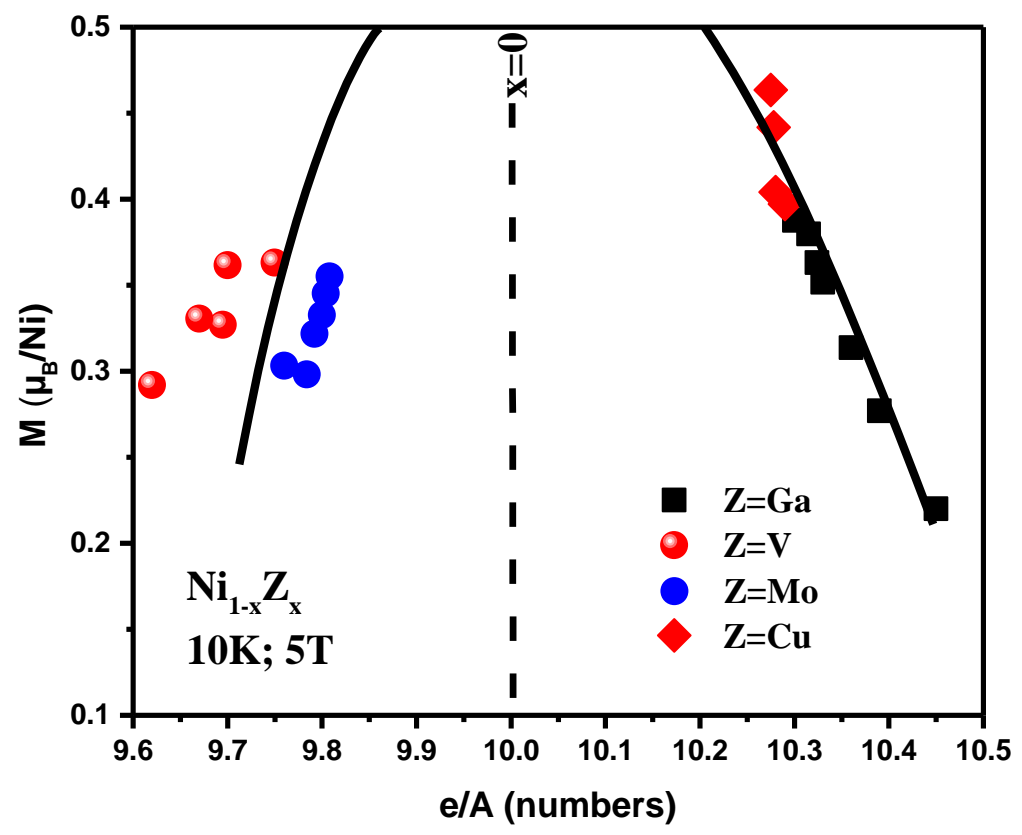

Fig. 5. Magnetization as a function of conduction electrons concentration (e/A) for $\mathrm{Ni}_{1-\mathrm{x}} \mathrm{Z}_{\mathrm{x}}(\mathrm{Z}=\mathrm{V}$, $\mathrm{Mo}, \mathrm{Cu}$, and $\mathrm{Ga}$ ) alloys (Slater-Pauling curves). 

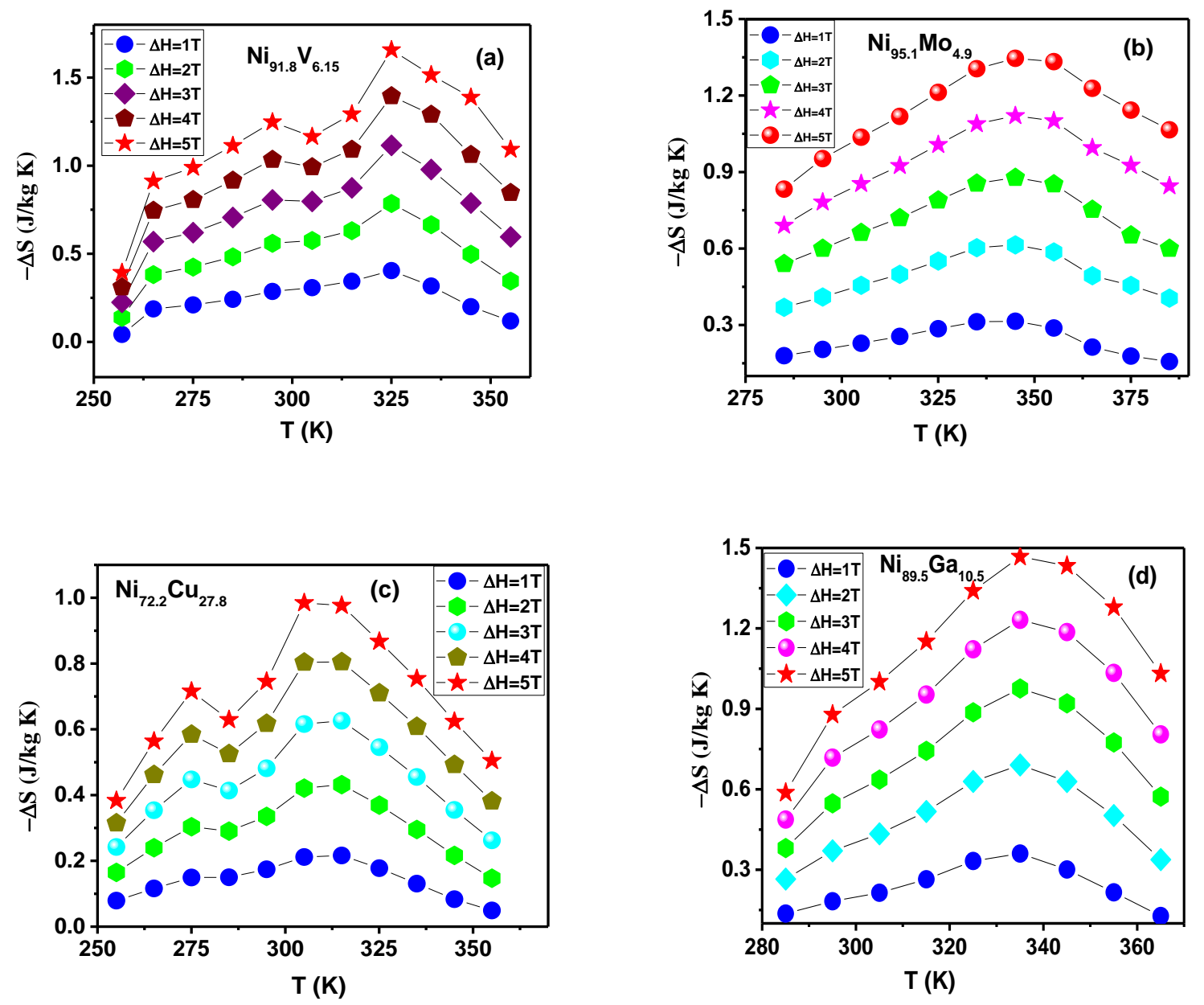

Fig. 6. Magnetic entropy changes $(\Delta \mathrm{S})$ of $\mathrm{Ni}_{1-\mathrm{x}} \mathrm{Z}_{\mathrm{x}}(\mathrm{Z}=\mathrm{V}, \mathrm{Mo}, \mathrm{Cu}$, and $\mathrm{Ga})$ alloys for a magnetic change of $\Delta \mathrm{H}=5 \mathrm{~T}$. 